\title{
Percutaneous Coronary Intervention for ST Elevation Myocardial Infarction-Stable After Successful Full-Dose Thrombolytic Therapy
}

National Cancer Institute

\section{Source}

National Cancer Institute. Percutaneous Coronary Intervention for ST Elevation

Myocardial Infarction-Stable After Successful Full-Dose Thrombolytic Therapy. NCI Thesaurus. Code C100001.

A percutaneous coronary intervention is necessary for a myocardial infarction that presents with ST segment elevation and the subject does not have recurrent or persistent symptoms, symptoms of heart failure or ventricular arrhythmia after a successful dose of thrombolytic therapy. (ACC) 